mechanism that restores liver mass after necrotic or apoptotic injury has occurred. The link between intracellular signals resulting in mitogenic and antiapoptotic effects of these agents remains to be completely dissected.

1. Kaplowitz, N.K., and DeLeve, L.D. 2003. Druginduced liver disease. Marcel Dekker Inc. New York, New York, USA. 773 pp.

2. Matsumura, H., et al. 2000. Necrotic death pathway in Fas receptor signaling. J. Cell Biol. 151:1247-1256.

3. Pinkoski, M.J., Brunner, T., Green, D.R., and Lin, T. 2000. Fas and Fas ligand in gut and liver. Am.J. Physiol. Gastrointest. Liver Physiol. 278:G354-G366.

4. Kanzler, S., and Galle, P.R. 2000. Apoptosis and the liver. Semin. Cancer Biol. 10:173-184.

5. Suzuki, Y., Ono, Y., and Hirabayashi, Y. 1998. Rapid and specific reactive oxygen species generation via NADPH oxidase activation during Fasmediated apoptosis. FEBS Lett. 425:209-212.

6. Jayanthi, S., Ordonez, S., McCoy, M.T., and Cadet, J.L. 1999. Dual mechanism of Fas-induced cell death in neuroglioma cells: a role for reactive oxygen species. Brain Res. Mol. Brain Res. 72:158-165.

7. Taub, R., Greenbaum, L.E., and Peng, Y. 1999. Transcriptional regulatory signals define cytokine- dependent and independent pathways in liver regeneration. Semin. Liver Dis. 19:117-127.

8. Kovalovich, K., et al. 2000. Increased toxininduced liver injury and fibrosis in interleukin-6 deficient mice. Hepatology. 31:149-159.

9. Kovalovich, K., et al. 2001. Interleukin- 6 protects against Fas-mediated death by establishing a critical level of anti-apoptotic hepatic proteins FLIP, Bcl-2, and Bcl-xL. J. Biol. Chem. 276:26605-26613.

10. Galun, E., Zeira, E., Pappo, O., Peters, M., and Rose-John, S. 2000. Liver regeneration induced by a designer human IL-6/sIL-6R fusion protein reverses severe hepatocellular injury. FASEB J. 14:1979-1987.

11. Ozaki, M., Haga, S., Zhang, H., Irani, K., and Suzuki, S. 2003. Inhibition of hypoxia/reoxygenationinduced oxidative stress in HGF-stimulated antiapoptotic signaling: role of PI3-K and Akt kinase upon rac1. Cell Death Differ. 10:508-515.

12. Haga, S., et al. 2003. Stat3 protects against Fasinduced liver injury by redox-dependent and -independent mechanisms. J. Clin. Invest. 112:989-998. doi:10.1172/JCI200317970.

13. Debonera, F., et al. 2001. Activation of interleukin6/STAT3 and liver regeneration following transplantation. J. Surg. Res. 96:289-295.

14. Li, W., Liang, X., Kellendonk, C., Poli, V., and Taub, R. 2002. STAT3 contributes to the mitogenic response of hepatocytes during liver regeneration. J. Biol. Chem. 277:28411-28417.
15. Levy, D.E., and Lee, C.-K. 2002. What does Stat3 do? J. Clin. Invest. 109:1143-1148. doi:10.1172/ JCI200215650.

16. Hirano, T., Ishihara, K., and Hibi, M. 2000. Roles of STAT3 in mediating the cell growth, differentiation and survival signals relayed through the IL-6 family of cytokine receptors. Oncogene. 19:2548-2556

17. Leu, J.I., Crissey, M.A., Leu, J.P., Ciliberto, G., and Taub, R. 2001. Interleukin-6-induced STAT3 and AP-1 amplify hepatocyte nuclear factor 1-mediated transactivation of hepatic genes, an adaptive response to liver injury. Mol. Cell. Biol. 21:414-424.

18. Ozaki, M., Suzuki, S., and Irani, K. 2002. Redox factor-1/APE suppresses oxidative stress by inhibiting the rac1 GTPase. FASEBJ. 16:889-890.

19. Ozaki, M., et al. 2000. Inhibition of the Rac1 GTPase protects against nonlethal ischemia/reperfusion-induced necrosis and apoptosis in vivo FASEB J. 14:418-429.

20. Grosch, S., Fritz, G., and Kaina, B. 1998. Apurinic endonuclease (Ref-1) is induced in mammalian cells by oxidative stress and involved in clastogenic adaptation. Cancer Res. 58:4410-4416.

21. Nakamura, H., Nakamura, K., and Yodoi, J. 1997. Redox regulation of cellular activation. Annu. Rev. Immunol. 15:351-369.

22. Hecht, N., et al. 2001. Hyper-IL-6 gene therapy reverses fulminant hepatic failure. Mol. Ther 3:683-687.

\title{
Selectin and selectin ligand binding: a bittersweet attraction
}

\section{Thomas M. Zollner and Khusru Asadullah}

Corporate Research Business Area Dermatology, Schering AG, Berlin, Germany

Inhibition of leukocyte migration into target organs has long been an attractive, though challenging, basis for anti-inflammatory strategies. However, to date, the manipulation of leukocyte rolling along blood vessels has not yielded successful new therapies. An important study (see the related article beginning on page 1008) may now open new avenues in this exciting field of anti-inflammatory therapies by introducing a putative inhibitor of poly- $N$-acetyllactosamine biosynthesis that affects selectin ligand activity and shows efficacy in a rodent skin inflammation model.

J. Clin. Invest. 112:980-983 (2003). doi:10.1172/JCI200319962.

Address correspondence to: Thomas M. Zollner, Corporate Research Business Area Dermatology, Schering AG, Muellerstrasse 178, D-13342 Berlin, Germany.

Phone: 49-30-468-17235;

Fax: 49-30-468-97235;

E-mail: Thomas.Zollner@Schering.de.

Conflict of interest: The authors are employees and stockholders of Schering AG, which is working on developing antiinflammatory compounds for the treatment of skin diseases.

Nonstandard abbreviations used: sialyl Lewis X $\left(\mathrm{sLe}^{\mathrm{X}}\right)$; cutaneous lymphocyteassociated antigen (CLA); $\beta 1$,4-galactosyltransferase (GalT); $\alpha 2,3$-sialyltransferase (ST3GalIV); $\alpha 1,3$-fucosyltransferase (FucT); P-selectin glycoprotein ligand-1 (PSGL-1); contact hypersensitivity (CHS); peracetylated4-fluorinated-D-glucosamine (4-F-GlcNAc).
Tissue-specific localization of T cells is a requirement for immune surveillance in the skin and in addition plays a pivotal role in the pathogenesis of numerous inflammatory skin disorders. Indeed, the evidence that $T$ cells are crucial factors in mediating psoriasis, allergic contact dermatitis, atopic dermatitis, and cutaneous $\mathrm{T}$ cell lymphomas is so strong that these diseases are now considered as $\mathrm{T}$ cell-mediated dermatoses (1). Consequently, insight into mechanisms of $\mathrm{T}$ cell recruitment to the skin (and other target organs) may lead to novel anti-inflammatory therapies, and the subject is therefore of particular interest.

\section{Selectin and selectin ligand interactions mediate leukocyte rolling along the endothelium}

The multistep cascade of $T$ cell migration has been well described (Figure 1), and the molecular basis for $\mathrm{T}$ cell skin homing has been reviewed recently (2). The first steps of $\mathrm{T}$ cell localization to all tissues include leukocyte tethering and rolling along the vessel wall, which is mediated primarily by interactions between selectin and selectin ligand (3). A number of studies have demonstrated the pivotal role of E- and P-selectin for leukocyte rolling as well as their overlapping and mutually compensating functions (4). Therefore, it was not surprising that a neutralizing antibody solely against E-selectin was found to be without beneficial effects in a recent clinical trial (5). Probably for these reasons, the development of a potent, but E-selectin-specific lowmolecular weight antagonist called ESA-2 (6) was stopped. The lesson learned from these findings was that potent and clinically active selectin antagonists have to interfere with at least two of the three selectins $(\mathrm{E}, \mathrm{P}$, and $\mathrm{L}$ ) in order to show in vivo efficacy. Some such antagonists have been reported recently $(7)$. 


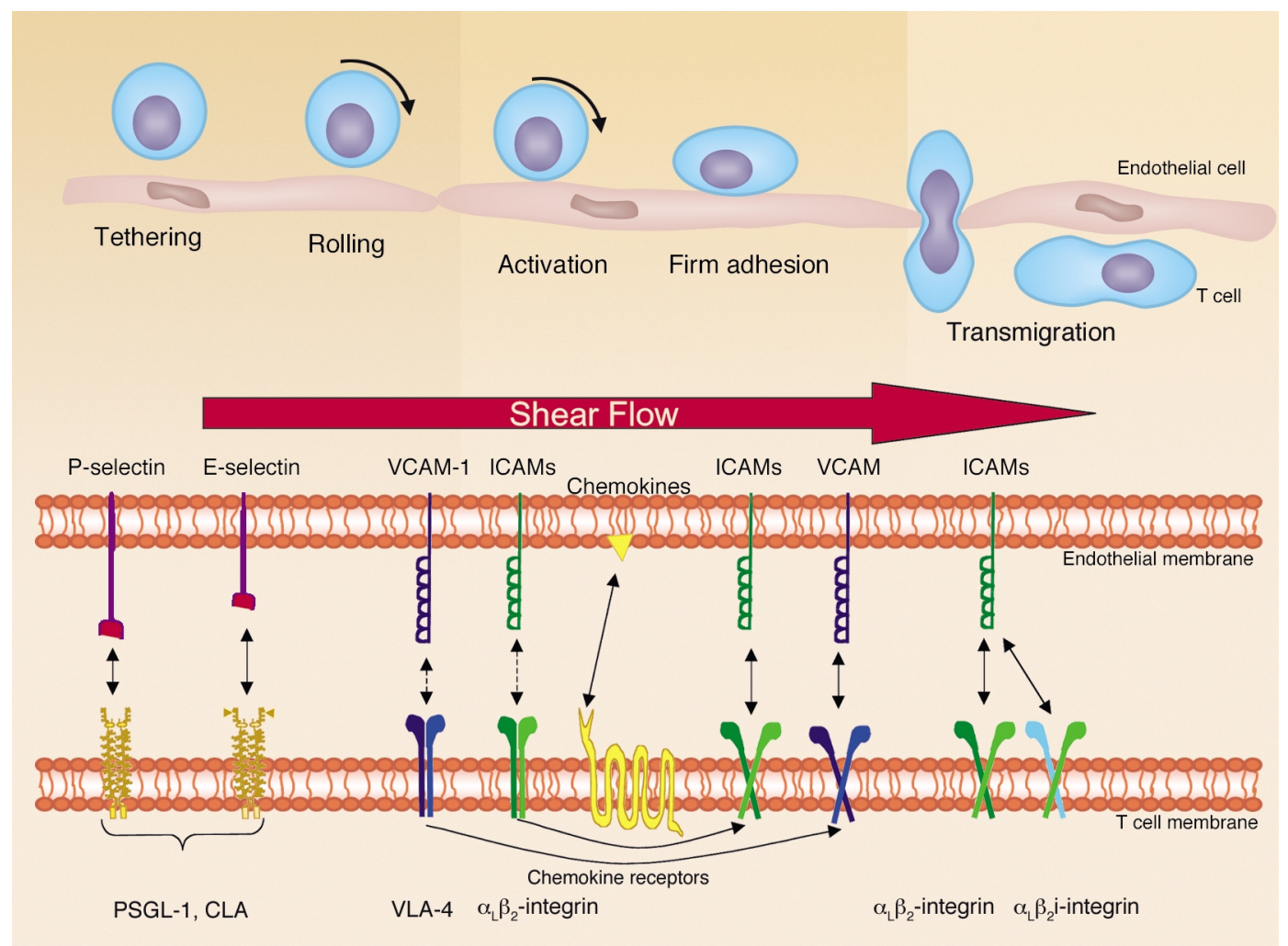

\section{Figure 1}

The multistep process of the interactions between lymphocytes and endothelial cells leading to T cell migration into skin. Selectin and selectin ligand interactions allow lymphocyte rolling along the endothelial lining. Lymphocyte chemokine receptors thereby come into contact with chemokines displayed by the endothelium; e.g., via proteoglycans leading to activation of integrins. This is necessary for subsequent firm adhesion of lymphocytes to the endothelium and the final transmigration through the blood vessel wall. VLA-4, very late antigen-4.

\section{Synthesis of sialyl Lewis $\mathrm{X}$ is} essential for selectin ligand binding The tetrasaccharide sialyl Lewis $\mathrm{X}$ $\left(\mathrm{sLe}^{\mathrm{X}}\right)$, which is closely related to cutaneous lymphocyte-associated antigen (CLA), binds to all three selectins and appears to be an interesting drug target. Its expression by $\mathrm{T}$ cells requires the action of multiple glycosyltransferases such as core $2 \beta 1,6-N$-acetylglucosaminyltransferase-I, $N$-acetylglucosamine-6-O-sulfotransferase, $\beta 1,4$-galactosyltransferases (GalTs), the $\alpha 2,3$-sialyltransferase (ST3GalIV), and $\alpha 1,3$-fucosyltransferases IV and VII (FucTIV and FucTVII). ST3GalIV, FucTIV, and FucTVII are responsible for synthesizing terminal sialofucosylations that serve as E-selectin ligands expressed by $\mathrm{P}$-selectin glycoprotein ligand-1 (PSGL-1) (8). Thus, these enzymes are potential drug targets and might even be targeted by small molecules in a manner suitable for oral administration. Among the best-characterized enzymes involved in lym- phocyte skin homing are FucTIV and FucTVII (9). FucTs catalyze the final step in the synthesis of selectin ligands. Mice deficient in FucTVII are characterized by a marked reduction of E-, P-, and L-selectin ligand activity and impaired leukocyte extravasation into inflamed tissue, indicating a major role for FucTVII in the generation of selectin ligands. In mice deficient for FucTVII and FucTIV, leukocyte rolling is completely absent, and contact hypersensitivity (CHS), which is substantially reduced in FucTVIIdeficient mice, is virtually absent $(10,11)$. Discovery of low-molecular weight antagonists of FucTVII, which plays the dominant role for selectin ligand production, is ongoing but has not yet reached clinical development $(12,13)$. Inhibition of FucTVII might be challenging, since FucTVII antagonists have to penetrate the cell and Golgi membrane to reach their target. More important is the fact that in humans, FucTIV may synthesize active selectin ligands in the absence of FucTVII, a compensatory mechanism that was observed in one patient carrying a homozygous missense mutation in the FucTVII gene (14).

\section{Inhibition of carbohydrate side chain elongation blocks E-selectin ligand expression and cutaneous immune reactions in vivo}

In this issue of the JCI, Dimitroff et al. (15) introduce a new strategy for the inhibition of selectin ligand production using the fluorinated analog of $\mathrm{N}$-acetylglucosamine - peracetylated4-fluorinated-D-glucosamine (4-F-GlcNAc) - as a glycosylation inhibitor. Terminal sLe ${ }^{\mathrm{x}}$ structures are expressed on poly- $N$-acetyllactosamines found on core $2 \mathrm{O}$ - and $\mathrm{N}$-linked glycans displayed by PSGL-1 (Figure 2). Consequently, compounds interfering with the synthesis of poly- $N$-acetyllactosamine structures should reduce selectin ligand activity and function. Indeed, Dimitroff and colleagues 
a Absence of 4-F-GlcNAc
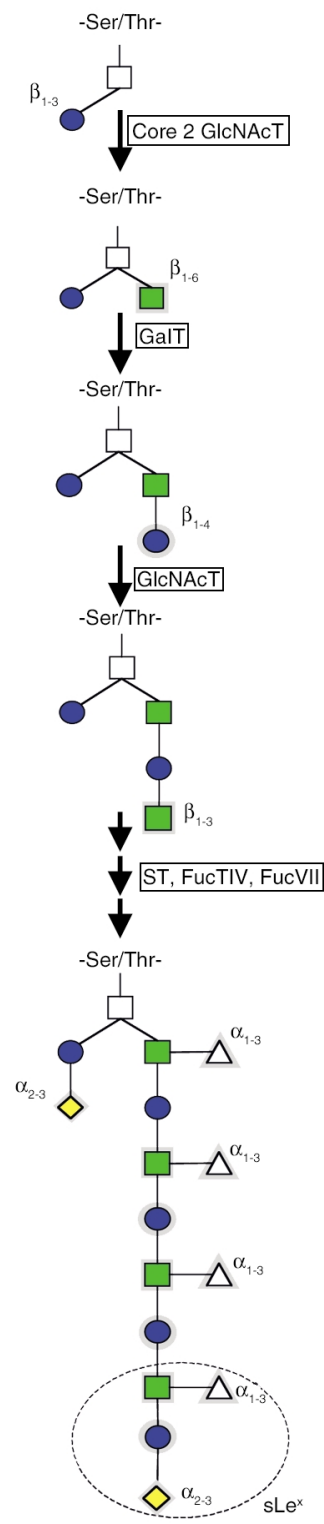

b Presence of 4-F-GlcNAc
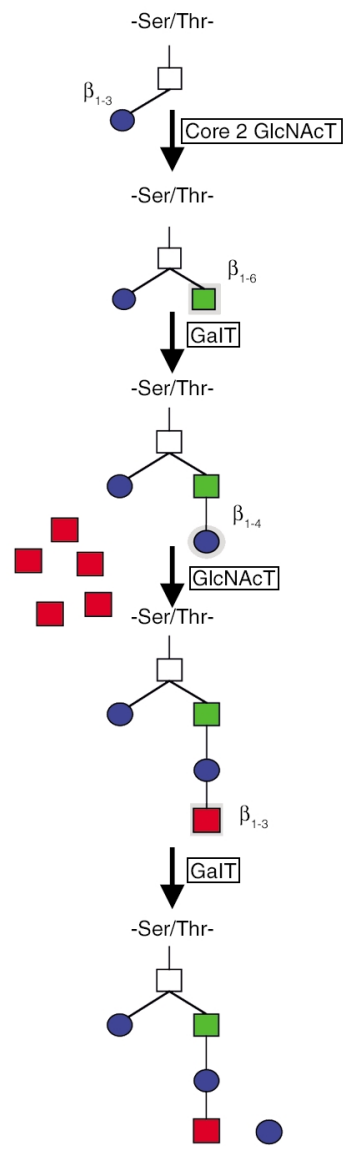

After incorporation of 4-F-GIcNAc into poly- $\mathrm{N}$-acetyllactosamine: no further chain elongation

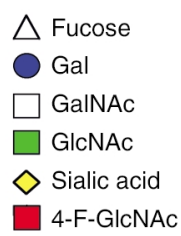

Figure 2

(a) Biosynthesis of core 2-type, sLe ${ }^{X}$-containing $O$-glycans. sLe ${ }^{X}$ is circled. (b) In the presence of 4-F-GIcNAc, the inhibitor is incorporated into poly- $N$-acetyllactosamine chains, which finally leads to termination of chain elongation.

demonstrated previously that 4-F-GlcNAc was directly incorporated into native CLA expressed on human $\mathrm{T}$ cells, indicating direct inhibition of poly- $N$-acetyllactosamine elongation (8). It is thought that after conversion to UDP-4-F-GlcNAc and addition to the poly- $N$-acetyllactosamine backbone, 4-F-GlcNAc blocks the addition of Gal to its 4-OH, leading to premature chain termination during $s L e^{\mathrm{X}}$ generation (8). In the present study, the authors extend their observations by neatly demonstrating blockade of lymphocyte E-selectin ligand expression in vivo and prevention of murine $\mathrm{CHS}$ reactions in the presence of $4-\mathrm{F}$ GlcNAc (15). Most interesting, 4-FGlcNAc inhibited CHS responses with an extremely high efficacy, which reached or even exceeded that of potent glucocorticosteroids or calcineurin inhibitors. On the other hand, in addition to their importance in cell-cell interaction, carbohydrate side chains on glycoproteins also play a significant role in protein confirmation, transport, and stability. Mice deficient in UDP-Gal: $N$-acetylglucosamine GalT - the enzyme responsible for elongation of poly- $N$-acetyllactosaminoglycans - are normal at birth but exhibit growth retardation and reduced life span. It was suggested that GalT, although dispensable during embryonic life, plays critical roles in the regulation of proliferation and differentiation of epithelial cells after birth (16). Currently, it is unclear whether incomplete, temporary inhibition of poly- $N$-acetyllactosaminoglycan elongation by 4-F-GlcNAc will have similar unwanted effects as observed in GalT-deficient mice. Nevertheless, selective glycosyltransferase inhibitors are expected to be more specific and may cause even fewer side effects. Although this indicates the need for further investigations and suggests that a novel drug is still a long way off, the present investigation has indicated that inhibition of selectin ligand activity can be achieved by antagonizing specific glycosyltransferases with small molecules and leads to anti-inflammatory effects in vivo. Remarkably, 4-F-GlcNAc only inhibited elicitation without modulating the sensitization phase in the CHS model (15) - a phenomenon that was also observed in FucTVII-deficient mice (11). This indicates that these strategies have the potential to be effective not only in preventive approaches but also in therapeutic modalities, which is important for the therapy of established disease. Moreover, the lack of inhibitory effects on the sensitization phase may even be an advantage, since it should allow a triggering of the immune response, which is important for host defense against pathogens.

\section{Acknowledgments}

We gratefully acknowledge helpful discussions with U. Voigtmann. Because of the extent and complexity of the lymphocyte homing field, we could not discuss many interesting studies, and we apologize to those authors whose excellent work could not be cited due to space limitations. 
1. Robert, C., and Kupper, T.S. 1999. Inflammatory skin diseases, $\mathrm{T}$ cells, and immune surveillance. N. Engl. J. Med. 341:1817-1828.

2. Schon, M.P., Zollner, T.M., and Boehncke, W.H. 2003. The molecular basis of lymphocyte recruitment to the skin - clues for the pathogenesis and selective therapies for inflammatory disorders. J. Invest. Dermatol. In press.

3. Kansas, G.S. 1996. Selectins and their ligands: current concepts and controversies. Blood. 88:3259-3287.

4. Labow, M.A., et al. 1994. Characterization of Eselectin-deficient mice: demonstration of overlapping function of the endothelial selectins. Cell. 1:709-720.

5. Bhushan, M., et al. 2002. Anti-E-selectin is ineffective in the treatment of psoriasis: a randomized trial. Br. J. Dermatol. 146:824-831.

6. Thoma, G., Banteli, R., Jahnke, W., Magnani, J.L., and Patton, J.T. 2001. A readily available, highly potent E-selectin antagonist. Angew. Chem. Int. Ed. Engl. 40:3644-3647.

7. Schon, M.P., et al. 2002. Efomycine M, a new spe- cific inhibitor of selectin, impairs leukocyte adhesion and alleviates cutaneous inflammation. Nat. Med. 8:366-372.

8. Dimitroff, C.J., Bernacki, R.J., and Sackstein, R 2003. Glycosylation-dependent inhibition of cutaneous lymphocyte-associated antigen expression: implications in modulating lymphocyte migration to skin. Blood. 101:602-610.

9. Schottelius, A.J., Hamann, A., and Asadullah, K. 2003. Role of fucosyltransferases in leukocyte trafficking: major impact for cutaneous immunity. Trends Immunol. 24:101-104.

10. Maly, P., et al. 1996. The alpha(1,3)fucosyltransferase Fuc-TVII controls leukocyte trafficking through an essential role in L-, E-, and P-selectin ligand biosynthesis. Cell. 86:643-653.

11. Smithson, G., et al. 2001. Fuc-TVII is required for T helper 1 and $\mathrm{T}$ cytotoxic 1 lymphocyte selectin ligand expression and recruitment in inflammation, and together with Fuc-TIV regulates naive $\mathrm{T}$ cell trafficking to lymph nodes. J. Exp. Med. 194:601-614.

12. Compain, P., and Martin, O.R. 2001. Carbohy- drate mimetics-based glycosyltransferase inhibitors. Bioorg. Med. Chem. 9:3077-3092.

13. Lee, L.V., et al. 2003. A potent and highly selective inhibitor of human alpha-1,3-fucosyltransferase via click chemistry. J. Am. Chem. Soc 125:9588-9589.

14. Bengtson, P., Lundblad, A., Larson, G., and Pahlsson, P. 2002. Polymorphonuclear leukocytes from individuals carrying the G329A mutation in the alpha 1,3-fucosyltransferase VII gene (FUT7) roll on E- and P-selectins. J. Immunol. 169:3940-3946

15. Dimitroff, C.J., Kupper, T.S., and Sackstein, R 2003. Prevention of leukocyte migration to inflamed skin with a novel fluorosugar modifier of cutaneous lymphocyte-associated antigen. J. Clin. Invest. 112:1008-1018. doi:10.1172/ JCI200319220.

16. Asano, M., et al. 1997. Growth retardation and early death of beta-1,4-galactosyltransferase knockout mice with augmented proliferation and abnormal differentiation of epithelial cells. EMBO J. 16:1850-1857.

\title{
Finding NEMO: genetic disorders of NF- $K B$ activation
}

\author{
Jordan S. Orange and Raif S. Geha
}

Division of Immunology, Children's Hospital and Department of Pediatrics, Harvard Medical School, Boston, Massachusetts, USA

The pathways between a receptor and transcriptional activation mediated by NF- $\kappa B$ are complex. The study of human gene mutations that result in dysregulation of these pathways has provided insight into the functions of individual components of the pathway, their interrelations, and the significance of these systems to the organism (see the related article beginning on page 1108).

J. Clin. Invest. 112:983-985 (2003). doi:10.1172/JCI200319960.

\section{Inducible activation of gene transcription}

NF- $\kappa B$ was recognized as a DNA-binding factor that exists in the cytoplasm of resting cells and that accumulates in the nucleus under appropriate conditions (1). The ability of NF- $\mathrm{NB}$ to shuttle between the cytoplasm and nucleus in a tightly regulated manner

Address correspondence to: Raif S. Geha, Division of Immunology, Children's Hospital, 300 Longwood Avenue,

Boston, Massachusetts 02115, USA.

Phone: (617) 355-7603; Fax: (617) 730-0528;

E-mail: Raif.Geha@TCH.Harvard.edu.

Conflict of interest: The authors have declared that no conflict of interest exists.

Nonstandard abbreviations used: ectodermal

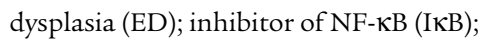
IKB kinase (IKK); NF- $\kappa B$ essential modulator (NEMO); TNF superfamily receptor (TNFSR); ectodysplasin-A (EDA); EDA receptor (EDAR); Toll-like receptor-4 (TLR-4). led to the exploration of a complex series of events leading to activationinduced gene expression, and to the discovery of factors that prevent the transit of NF- $\kappa \mathrm{B}$ into the nucleus (2). Receptor-mediated NF- $\kappa \mathrm{B}$ activation of gene transcription and its stringent control are fundamental to cell development, survival, and function. In this issue of the JCI, Courtois and colleagues report a novel human mutation in a protein that negatively regulates NF- $\mathrm{KB}$ activation (3). The resultant mutant dominantly inhibits the activation of NF- $\mathrm{KB}$ (see below) and gives rise to a clinical syndrome of ectodermal dysplasia (ED) and susceptibility to infection.

NF- $\mathrm{KB}$ activity is imparted by a protein dimer selected from five mammalian homologues: p50, p52, p65 (RelA), Rel, and RelB (p50 and p52 are derived from larger precursors, p105 and $\mathrm{p} 100$, respectively). The majority of dimers formed by these individual $\mathrm{NF}-\kappa \mathrm{B}$ members are capable of activating transcription by binding to $\kappa \mathrm{B}$ sites in DNA. The dimerization of these molecules occurs through a conserved N-terminal Rel homology domain (RHD). Importantly, the RHD also serves as the binding site for one of several inhibitors of NF- $\kappa B$ (I $\kappa B s$ ). An $I \kappa B$ can physically interfere with $\mathrm{NF}-\kappa \mathrm{B}$ dimerization or block nuclear localization sequences within the $\mathrm{NF}-\kappa \mathrm{B}$ member. The family of molecules possessing these activities consists of at least seven members: I $\mathrm{K} \mathrm{B} \alpha$, $\mathrm{I} \kappa \mathrm{B} \beta, \mathrm{I} \kappa \mathrm{B} \varepsilon, \mathrm{I} \kappa \mathrm{B} \gamma, \mathrm{Bcl}-3$, and inhibitory domains of the p105 and p100 precursor proteins. The cytoplasmic association of an $I \kappa B$ and a NF- $\kappa B$ member is controlled by the phosphorylation of the $I \kappa B$, which leads to its ubiquitination and proteosomal degradation (Figure 1). The release of an NF- $\mathrm{BB}$ protein from I $\mathrm{I} B$ allows it to participate in dimer formation, translocate to the nucleus, and activate transcription. The phosphorylation of I $\mathrm{B}$, therefore, is a critical regulatory step in $\mathrm{NF}-\kappa \mathrm{B}$ function.

\section{NF- $\kappa \mathrm{B}$ activation}

Phosphorylation of I $\mathrm{I} B$ is mediated by an IKB kinase (IKK), a large, multisubunit signaling complex (signalosome) capable of binding I $\kappa \mathrm{B}$ as well as other upstream regulators. The classical IKK signalosome consists of two catalytic subunits, IKK $\alpha$ and IKK $\beta$, and a regu- 